\title{
Prediction of the non-ideal detonation performance of commercial explosives using the DeNE and JWL++ codes
}

\author{
S. Esen ${ }^{1, * \dagger}$, P. C. Souers ${ }^{2}$ and P. Vitello ${ }^{2}$ \\ ${ }^{1}$ Swedish Blasting Research Centre, Box 47047, S-10074 Stockholm, Sweden \\ ${ }^{2}$ Energetic Materials Center, Lawrence Livermore National Laboratory, Livermore, CA 94550, U.S.A.
}

\begin{abstract}
SUMMARY
The non-ideal detonation performance of two commercial explosives is determined using the DeNE and JWL++ codes. These two codes differ in that DeNE is based on a pseudo-one-dimensional theory which is valid on the central stream-tube and capable of predicting the non-ideal detonation characteristics of commercial explosives as a function of the explosive type, rock properties and blasthole diameter. On the other hand, JWL++ is a hydrocode running in a 2-D arbitrary LagrangianEulerian code with CALE-like properties and can determine the flow properties in all stream lines within the reaction zone. The key flow properties (detonation velocity, pressure, specific volume, extent of reaction and reaction zone length) at the sonic locus on the charge axis have been compared. In general, it is shown that the flow parameters determined using both codes agree well. The pressure contours determined using the JWL++ are analysed in detail for two explosives at $165 \mathrm{~mm}$ blastholes confined in limestone and kimberlite with a view to further investigate the explosive/rock interface. The DeNE and JWL++ codes have been validated using the measured in-hole detonation velocity data. Copyright (c) 2005 John Wiley \& Sons, Ltd.
\end{abstract}

KEY WORDS: non-ideal detonation; commercial explosives; detonation velocity; curvature; explosive/ rock interface

\section{INTRODUCTION}

Although explosives have been used for rock blasting for over a century, plausible scientific theories on rock fragmentation by blasting have only emerged only during the last few decades. However, the rock breakage process is still not as fully understood and controlled to the level now demanded by the blasting customers. Computer modelling as an engineering tool has been extended to blasting to carry out extensive computations in blast simulations. Nevertheless, the validity of these models is dependent on the knowledge of the explosive/rock interaction

\footnotetext{
${ }^{*}$ Correspondence to: S. Esen, Swebrec at Lulea University of Technology, Box 47047, Mejerivägen 4 (T-stop Liljeholmen), S-10074 Stockholm, Sweden.

†E-mail: sedat@svebefo.se
} 
process. Therefore, the prediction of the explosive performance is crucial to the understanding of the explosive/rock interaction process and therefore the rock breakage.

The ability to predict the realistic explosive performance in rock blasting depends on the fundamental understanding of detonation theory. Detonation modelling can be grouped into ideal and non-ideal detonation [1,2]. Explosive performance has generally been computed from ideal detonation codes, which were primarily developed for military explosives. They have limited applications in predicting the performance of commercial explosives as the calculated detonation properties assume independence of charge diameter and confinement. Since they provide the estimates of the maximum performance attainable from an explosive and some input to the non-ideal detonation model, they are useful in modelling the non-ideal detonation.

A number of non-ideal detonation theories or models have been proposed in the literature to predict the detonation behaviour of commercial explosives. Most widely used models include the Wood-Kirkwood theory [3], detonation shock dynamics [4,5] and slightly divergent flow theory [6], which is an extension of the Wood-Kirkwood theory [3]. The common feature in these models is that they require experimental unconfined velocity of detonation (VoD) versus charge diameter data to calibrate the kinetic parameters. Unlike $\mathrm{CPeX}$ which is based on the slightly divergent flow theory, these models have not been applied to rock blasting and usually applied to the unconfined explosive charges or charges confined by metal confinement. It was noted that the confinement calculations in CPeX code are not reliable [7]. Therefore, there is a need for alternative non-ideal detonation models for predicting the performance of the commercial explosives in rock blasting.

Two detonation codes are used in this paper to investigate the non-ideal detonation characteristics and explosive/rock interface of commercial explosives. These include DeNE (detonics of non-ideal explosives) developed by Esen [1] based on the slightly divergent detonation theory and a hydrocode namely JWL++ developed by Souers et al. [8]. The performances of two commercial explosives confined in two different rock types have been predicted and compared with these codes.

\section{DETONATION CHARACTERISTICS OF COMMERCIAL EXPLOSIVES}

If we detonate a cylindrical column of explosive and measure the detonation velocity, we will find that VoD decreases as the diameter of the column decreases. This effect is caused by a pressure fall at the side of the column. When the diameter is large the losses are small relative to the energy production at the wave front. If the column diameter is small the energy losses are larger relative to the energy generated at the wave front. The decrease in velocity continues until a diameter (failure diameter) is reached where the energy losses are so great relative to the energy production that the detonation fails to propagate [9]. It is also widely recognized that increased confinement can have a similar effect to that of increased charge diameter.

In a non-ideal situation, as represented in Figure 1, the shock front is always curved, the flow of the reaction products diverges and reaction is never complete in the detonation zone. The detonation driving zone (DDZ) terminates at the sonic line and contributes to the support of the detonation process [7]. In this case, the detonation velocity may approach, but never exceeds, the ideal detonation velocity [10]. It is widely recognized that the degree of 


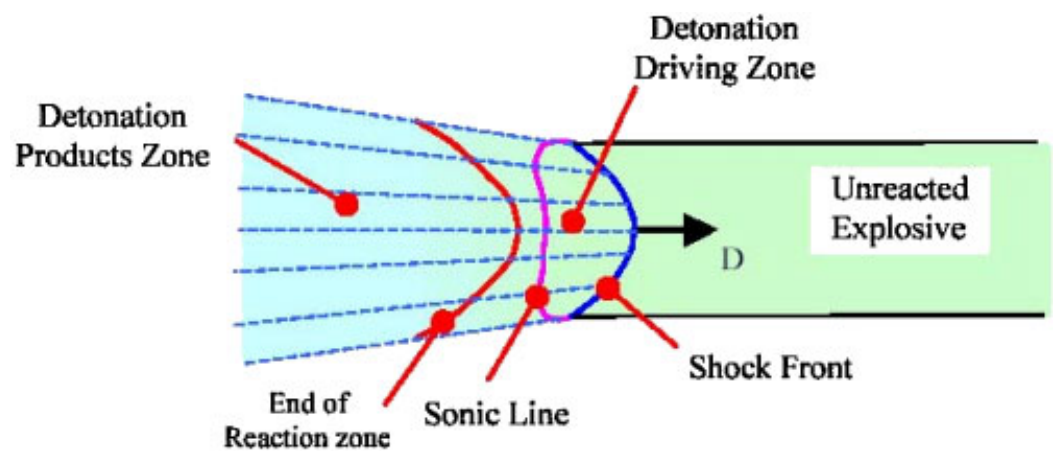

Figure 1. Non-ideal (2-D) detonation representation [7].

non-ideality of an explosive can be judged by the difference in the ideal and the actual detonation velocity.

The flow behind the sonic line is supersonic, so that perturbations such as compression and rarefaction waves, which move at the local sound speed, can never catch up with the DDZ, and cannot therefore contribute to or diminish the speed of the detonation wave. The rarefaction (Taylor wave) which occurs in the supersonic, still reactive, flow between the sonic line and the end of the reaction zone is of importance, especially with commercial explosives which may have slow energy-releasing reactions and can contribute substantially to the blast [7].

\section{DESCRIPTION OF THE NON-IDEAL DETONATION CODES}

\subsection{The DeNE code}

The DeNE is a hybrid non-ideal detonation code combining the proven Kirby and Leiper's [6] slightly divergent flow analysis, polytropic equation of state (EoS), simple pressure-dependent rate law and statistical expressions to model the effect of confinement on detonation. The code includes two models: DDZ and Taylor wave. The reactive fluid flow in the DDZ is modelled by differential/algebraic equations in a parameterized boundary value format. The output of the DDZ model is then used to determine the isentrope from the sonic line to an arbitrary end pressure.

3.1.1. The DDZ model. The DDZ model employs the slightly divergent flow analysis, which requires the numerical solution of differential/algebraic equations involving the shock front and sonic locus. The key simplifications and assumptions in the slightly divergent flow theory are:

- Steady state detonation.

- Lagrangian (shock frame formulation).

- Cylindrical co-ordinates-rate stick.

- Pseudo-one-dimensional theory applies to the central stream-tube area. 
- Radial velocity on the central stream-tube is zero. The divergence term is considered in an approximate manner.

- Empirical relations are assumed for the shock front curvature and shape of the isobars.

The theory tends to be valid for cases of modest reaction zone lengths and small divergence/ large shock front radius of curvature. The slightly divergent flow analysis has been fully described by Kirby and Leiper [6], Braithwaite et al. [11], Fickett and Davis [12] and Sturgeon et al. [13]. The theory gives a system of five ordinary differential equations (ODEs), four algebraic equations (AEs) and eight boundary conditions (BCs).

The ODEs are

$$
\begin{aligned}
\rho u \dot{u}+\dot{p} & =0 \\
\dot{A} & =2 A \omega \\
\dot{\lambda} & =R(\lambda, p) \\
\dot{\omega} & =\frac{-\dot{u}}{R\left(x, x_{\mathrm{CJ}}, d\right)} \\
\dot{x} & =u
\end{aligned}
$$

The AEs are

$$
\begin{aligned}
E & =E(p, v, \lambda) \\
E+p v+\frac{u^{2}}{2} & =\frac{D^{2}}{2} \\
A \rho u-\rho_{0} D & =0 \\
v & =\frac{1}{\rho}
\end{aligned}
$$

The BCs at $t=0$ (shock front) are

$$
\begin{aligned}
& u=u_{\mathrm{s}}(D) \\
& A=1 \\
& \lambda=0 \\
& \omega=\frac{D-u_{\mathrm{s}}(D)}{R_{\mathrm{S}}\left(x_{\mathrm{CJ}}, d\right)} \\
& x=0
\end{aligned}
$$


and the $\mathrm{BCs}$ at $t=t_{\mathrm{CJ}}$ (sonic locus) are

$$
\begin{aligned}
& u=c(p, v, \lambda) \\
& \omega=\frac{\sigma(p, v, \lambda, c) \dot{\lambda}}{2} \\
& x=x_{\mathrm{CJ}}
\end{aligned}
$$

The physical constraints are

$$
\begin{gathered}
0<u \leqslant c(p, v, \lambda), \quad 0 \leqslant \lambda \leqslant 1 \\
p, \rho, v>0, \quad A \geqslant 1
\end{gathered}
$$

The sound speed $c$ and the thermicity coefficient $\sigma$ are defined by the following relations [12]:

$$
\begin{gathered}
c^{2}=v^{2}\left[\frac{p+\left(\frac{\partial E}{\partial v}\right)_{\mathrm{p}, \lambda}}{\left(\frac{\partial E}{\partial p}\right)_{v, \lambda}}\right] \\
\sigma=\frac{1}{\rho c^{2}}\left(\frac{-\left(\frac{\partial E}{\partial \lambda}\right)_{\mathrm{p}, v}}{\left(\frac{\partial E}{\partial p}\right)_{\lambda, v}}\right)
\end{gathered}
$$

The reactive $\operatorname{EoS} E(p, v, \lambda)$ is [14]

$$
E=p v\left(\frac{1-\lambda}{\gamma_{\mathrm{x}}-1}+\frac{\lambda}{\gamma_{\mathrm{p}}-1}\right)-\lambda q+(1-\lambda) E_{\mathrm{t}}
$$

in which

$$
\gamma_{\mathrm{p}}=\gamma_{0}+\gamma_{1} \frac{\rho}{\rho_{0}}+\gamma_{2} \frac{\rho^{2}}{\rho_{0}^{2}} \quad \text { or } \quad \gamma_{\mathrm{p}}=\gamma_{0}+\gamma_{1} \frac{v_{0}}{v}+\gamma_{2} \frac{v_{0}^{2}}{v^{2}}
$$

where the subscript 0 is for the initial state; $\mathrm{x}$ is for the unreacted phase; $\mathrm{p}$ is for the product phase; $\gamma$ is the adiabatic gamma coefficient; $q$ is the heat of reaction; $E_{\mathrm{t}}$ is the turbulent stored energy, and $\rho_{0}$ is the unreacted explosive porous density. The $\gamma_{i}$ constants are determined by requiring that the correct values for $(\partial \ln p / \partial \ln v)_{\mathrm{s}}$ are returned at the CJ state and at infinite expansion. These are taken from an ideal detonation code. $\gamma_{0}$ is set equal to the ideal gas value.

The rate law $R(\lambda, p)$ is [1]

$$
\dot{\lambda}=k(1-\lambda)\left(\frac{p}{P_{\text {ref }}}\right)^{2}
$$

where $k$ is the rate constant and $P_{\text {ref }}$ is the reference pressure with value $1 \mathrm{GPa}$. 
The functions of $R\left(x, x_{\mathrm{CJ}}, d\right)$ and $R_{\mathrm{s}}\left(x_{\mathrm{CJ}}, d\right)$ are [1]

$$
\begin{aligned}
R\left(x, x_{\mathrm{CJ}}, d\right) & =\frac{R_{\mathrm{S}}^{2}\left(x_{\mathrm{CJ}}, d\right)-x R_{\mathrm{S}}\left(x_{\mathrm{CJ}}, d\right)+\frac{\zeta x^{2}}{2}}{R_{\mathrm{S}}\left(x_{\mathrm{CJ}}, d\right)-\zeta x} \\
R_{\mathrm{S}} & =\alpha\left(d-\beta x_{\mathrm{CJ}}\right)
\end{aligned}
$$

where ${ }^{\bullet} \equiv \mathrm{d} / \mathrm{d} t$ represents differentiation with respect to time; $u(\mathrm{~km} / \mathrm{s})$ is the particle velocity relative to the shock front; $p(\mathrm{GPa})$ is the pressure; $A$ is the area of a stream-tube of fluid which had unit area at the shock front; $R(\lambda, p)$ is the reaction rate vector; $\lambda$ is the extent of chemical reaction varying from 0 for the unreacted explosive (no reaction) to 1 for the detonation products (complete reaction); $\omega\left(\mu \mathrm{s}^{-1}\right)$ is the divergence defined as the radial velocity of the stream-tube at unit distance from the axis of the cylinder; $E(\mathrm{MJ} / \mathrm{kg})$ is the specific internal energy; $v\left(\mathrm{~cm}^{3} / \mathrm{g}\right)$ is the specific volume; $\rho\left(\mathrm{g} / \mathrm{cm}^{3}\right)$ is the fluid density; $x(\mathrm{~mm})$ is the distance downstream of the shock front, and $R\left(x, x_{\mathrm{CJ}}, d\right)$ is the radius of curvature of an isobar at a distance $x(\mathrm{~mm})$ downstream of the shock front. $R_{\mathrm{S}}\left(x_{\mathrm{CJ}}, d\right)$ is the radius of the curvature of the shock front. $d(\mathrm{~mm})$ is the charge diameter; $u_{\mathrm{s}}(\mathrm{km} / \mathrm{s})$ is the shock front particle velocity; $D(\mathrm{~km} / \mathrm{s})$ is the detonation velocity; $c(\mathrm{~km} / \mathrm{s})$ is the local fluid sound speed; $\sigma$ is the thermicity coefficient of the fluid, and $x_{\mathrm{CJ}}(\mathrm{mm})$ is the $\mathrm{CJ}$ distance (reaction zone length). $\xi$ is a curvature parameter. $\alpha$ and $\beta$ are experimentally determined parameters with values $\alpha=3.75$ and $\beta=6.33$, respectively [1].

Following Braithwaite et al. [11], the algebraic constraints Equations (6)-(9) are differentiated to obtain

$$
\begin{aligned}
\dot{E}-\dot{p} \frac{\partial E(p, v, \lambda)}{\partial p}-\dot{v} \frac{\partial E(p, v, \lambda)}{\partial v}-\dot{\lambda} \frac{\partial E(p, v, \lambda)}{\partial \lambda} & =0 \\
\dot{E}+\dot{p} v+\dot{v} p+u \dot{u} & =0 \\
\dot{A} \rho u+A \dot{\rho} u+A \rho \dot{u} & =0 \\
\dot{v} & =-\frac{\dot{\rho}}{\rho^{2}}
\end{aligned}
$$

$\dot{A}$ and $\dot{\rho}$ are substituted from Equation (2) and Equation (29), respectively, into Equation (28) and use Equation (9), giving

$$
2 A \omega \rho u-\left(\frac{A \rho u}{v}\right) \dot{v}+A \rho \dot{u}=0
$$

Since $A, \rho>0$, Equation (30) becomes

$$
\dot{v}=\frac{v}{u}(\dot{u}+2 \omega u)
$$


Use Equation (29) and Equation (31) to obtain

$$
\dot{\rho}=-\frac{(\dot{u}+2 \omega u)}{u v}
$$

Substitute Equation (8) into Equation (1) to yield

$$
\rho_{0} D \dot{u}+\dot{p} A=0
$$

The functions $E, c$ and $\sigma$ are always defined under the rule that the adiabatic equation

$$
\dot{p}=-\rho u^{2}\left(\frac{\sigma \dot{\lambda}-2 \omega}{1-u^{2} / c^{2}}\right)
$$

must be satisfied [6].

Substituting Equations (34) and (8) into Equation (33),

$$
\dot{u}=\frac{u c^{2}(\sigma \dot{\lambda}-2 \omega)}{c^{2}-u^{2}}
$$

where $\sigma \dot{\lambda}$ is called the thermicity product which gives the pressure change due to reaction.

Hence, we have nine ODEs for nine variables $(u, p, A, \lambda, \omega, E, v, \rho, x)$ :

$$
\begin{aligned}
& \dot{u}=\frac{u c^{2}(\sigma \dot{\lambda}-2 \omega)}{c^{2}-u^{2}} \\
& \dot{p}=-\rho u \dot{u} \\
& \dot{A}=2 A \omega \\
& \dot{\lambda}=k(1-\lambda)\left(\frac{p}{P_{\mathrm{ref}}}\right)^{2} \\
& \dot{\omega}=\frac{-\dot{u}}{R\left(x, x_{\mathrm{CJ}}, d\right)} \\
& \dot{E}=\dot{p} \frac{\partial E(p, v, \lambda)}{\partial p}+\dot{v} \frac{\partial E(p, v, \lambda)}{\partial v}+\dot{\lambda} \frac{\partial E(p, v, \lambda)}{\partial \lambda} \\
& \dot{v}=\frac{v}{u}(\dot{u}+2 \omega u) \\
& \dot{\rho}=-\frac{(\dot{u}+2 \omega u)}{u v} \\
& \dot{x}=u
\end{aligned}
$$


Equation (36) exhibits singularity whenever $u=c$ and $2 \omega=\sigma \dot{\lambda}$ though it is not perceived in the original form Equations (1)-(17). Thus, Equation (36) cannot be solved when $t=t_{\mathrm{CJ}}$. However, at all points $t \in\left[0, t_{\mathrm{CJ}}\right)$, Equation (36) has a solution.

The problem is treated as an initial value problem provided that the BCs (Equations (15)(17)) at the sonic line are satisfied. Thus, an ODE solver would suffice. The initial conditions are given in Appendix A. The code employs the Bulirsch-Stoer extrapolation method as the numerical solution technique for solving the ODEs [1].

The solution of the DDZ model requires the determination of the two key flow parameters for a given confinement (rock) type: the confined $\mathrm{VoD}$ and the radius of the curvature of the shock front. These parameters are predicted using the statistical relations in the absence of analytical models. This should permit acceptable representations of the non-ideal detonation problem for commercial explosives used in rock blasting operations.

Based on the experimental in-hole VoD measurements, the following empirical model has been developed to determine the confined $\operatorname{VoD}[1,15]$ :

$$
D_{\mathrm{c}}=D_{\mathrm{u}}\left(1+\left(\frac{D_{\mathrm{CJ}}-D_{\mathrm{u}}}{D_{\mathrm{CJ}}}\right)\left(\frac{M}{1+a M^{b}}\right)\right)
$$

where

$$
M=\frac{\rho_{\mathrm{r}} v_{\mathrm{p}}}{\rho_{0} D_{\mathrm{u}}}
$$

and $a$ and $b$ are constants with values 4.563 and 0.688 , respectively; $D_{\mathrm{c}}$ is the confined VoD $(\mathrm{km} / \mathrm{s}) ; D_{\mathrm{u}}$ is the unconfined $\mathrm{VoD}$ of an explosive at a given charge diameter $(\mathrm{km} / \mathrm{s}) ; D_{\mathrm{CJ}}$ is the ideal $\operatorname{VoD}(\mathrm{km} / \mathrm{s}) ; \rho_{\mathrm{r}}$ is the rock density $\left(\mathrm{g} / \mathrm{cm}^{3}\right) ; v_{\mathrm{p}}$ is the P-wave velocity of the intact rock $(\mathrm{km} / \mathrm{s})$ and $\rho_{0}$ is the density of the unreacted explosive $\left(\mathrm{g} / \mathrm{cm}^{3}\right)$.

The above model requires the prediction of the unconfined $\mathrm{VoD}$ at a given charge diameter. In order to characterize a commercial explosive, a number of unconfined tests should be carried at a wide range of charge diameters. The following equation is shown to be the most capable of modelling the unconfined detonation velocity data of the explosives with varying non-ideality [15]:

$$
\frac{D_{\mathrm{u}}}{D_{\mathrm{CJ}}}=\frac{1}{1+m\left(\frac{1}{d}\right)+n\left(\frac{1}{d}\right)^{2}}
$$

where $m$ and $n$ are fitting constants.

In the absence of analytical models and/or experimental measurements, the following simple empirical relationship proposed by Braithwaite [16] is used to predict the radius of the confined shock curvature $\left(R_{\mathrm{S}_{\mathrm{c}}}\right)$ :

$$
\frac{R_{\mathrm{s}_{\mathrm{c}}}}{R_{\mathrm{S}_{\mathrm{u}}}}=1+\frac{\rho_{\mathrm{r}} v_{\mathrm{p}}}{\rho_{0} D_{\mathrm{c}}}
$$

where $R_{\mathrm{S}_{\mathrm{u}}}$ is the radius of the unconfined shock curvature given in Equation (25).

The DDZ model presented above has been coded in $\mathrm{C}++$ programming language using an ODE solver included in the numerical library provided by Schilling and Harris [17]. The input parameters are the ideal detonation data (unreacted explosive density, ideal detonation 
velocity, heat of reaction, ideal (expanded) gas gamma and ideal CJ gamma), unreacted explosive properties (mass fraction of liquid, solid and liquid densities, Hugoniot parameters); unconfined VoD versus charge diameter data, blasthole diameter and intact rock properties (density and P-wave velocity). The code outputs the detonation properties (detonation velocity, detonation pressure, extent of chemical reaction, specific internal energy, density, specific volume, particle velocity, sound speed, stream-tube area, divergence, distance and time downstream of the shock front) at the DDZ, which are also input to the Taylor wave model [1].

3.1.2. The Taylor wave model. The gamma law is preferred in this study to estimate the isentrope over the range from the sonic locus to the pressure to which the expansion ends. It is described by the following relation [18]:

$$
p=p_{\mathrm{CJ}}\left(\frac{v_{\mathrm{CJ}}}{v}\right)^{\gamma}
$$

where the subscript $\mathrm{CJ}_{\mathrm{J}}$ is for the $\mathrm{CJ}$ state. $p_{\mathrm{CJ}}, v_{\mathrm{CJ}}$ and $\gamma$ are obtained from the DDZ model.

It is believed that the gamma law should suffice to predict the isentrope following the sonic locus. The Taylor wave model used in this study should be viewed as a model which provides only a first approximation for the flow analysis.

\subsection{The $J W L++$ code}

Our hydrocode model is the JWL++ by Souers et al. [8], a reactive flow model running in a 2-D arbitrary Lagrangian-Eulerian (ALE) code with CALE-like properties. The problem is broken into zones in which the model runs on every cycle of time, so that the result is integrative. The code is Lagrange with Eulerian relaxation, so that mass is assigned to specific zones but can be allowed to flow out in certain places in order to avoid zone tangling. The model uses a detonation rate to make the explosive give up its energy over time. This rate causes the size effect, detonation front curvature and decrease of detonation velocity. In the code, a constant rate constant $G_{1}$ is used for all radii of a given explosive. The rate is given by Souers et al. [8]

$$
\frac{\mathrm{d} \lambda}{\mathrm{d} t}=G_{1}(p+Q)^{b_{1}}(1-\lambda)
$$

where $G_{1}$ the rate constant, and $b_{1}$ the power of the pressure (usually set to 1 ). The sum of pressure $p$ and artificial viscosity $Q$ make up the hydrostatic pressure in the model.

The JWL++ contains the following unreacted and reacted EoSs.

(1) An unreacted explosive Murnahan EoS [8]

$$
p=\frac{1}{n \kappa}\left(\frac{1}{v^{n}}-1\right)
$$

with

$$
\begin{aligned}
& n=4 S_{1}-1 \\
& \kappa=\frac{1}{\rho_{0} C_{0}^{2}}
\end{aligned}
$$


where $v=\rho_{0} / \rho$ is the relative volume; $n$ and $\kappa$ are the unreacted EoS coefficients derived from measured $U_{\mathrm{s}}-u_{\mathrm{p}}$ (shock velocity-particle velocity) relations; $C_{0}$ and $S_{1}$ are the shock Hugoniot parameters for the unreacted explosive.

(2) A reacted JWL in the C-term form [8]

$$
p=A \exp \left(-R_{1} v\right)+B \exp \left(-R_{2} v\right)+\frac{C}{v^{\omega+1}}
$$

where $A, B, C, R_{1}, R_{2}$, and $\omega$ are constants to be calibrated, and $v$ is the relative volume. The detonation energy along the isentrope, $E_{\mathrm{d}}(v)$, at relative volume, $v$, is obtained by

$$
E_{\mathrm{d}}(v)=E_{0}-E_{\mathrm{s}}(v)
$$

where $E_{0}$ is the total (chemical) detonation energy and $E_{\mathrm{s}}$ is the internal energy, obtained by integrating the JWL equation as a function of $v$. Tables of the constants for the JWL EoS, calibrated for many explosives are available and the EoS is easy to calibrate to make it agree with experiments modelled with a computer program. The JWL EoS has proven very useful for engineering calculations, and has been widely used [19].

The JWL++ determines the flow properties in all stream lines in the DDZ. This is a major advantage over the slightly divergent flow analysis.

The coarsest zoning allowable is about four zones in the reaction zone, and we have gone finer by 3-9 times. The length of the cylinder is set at about 5 outer rock diameters to reach the steady state detonation velocity.

JWL++ does not deliver a CJ pressure directly. The maximum pressure (and minimum volume) is from the spike, which is created by compressing the unreacted explosive, so that the spike pressure is roughly $40 \%$ higher than the CJ pressure. The sonic plane (i.e. the back of the reaction zone) is taken to be the CJ point in ZND theory, and we compare values taken here with the analytic model.

The back of the reaction zone is found from the relation

$$
\left(u_{\mathrm{p} x}^{2}+u_{\mathrm{p} y}^{2}\right)^{1 / 2}+C-D=0
$$

where $u_{\mathrm{p}}$ is the particle velocity, $C$ is the sound speed and $D$ is the detonation velocity obtained in the problem.

\section{INPUT PARAMETERS AND THE SIZE EFFECT DATA}

In this study, two explosives with different degree of non-ideality are chosen. These are pure ANFO with a density of $0.80 \mathrm{~g} / \mathrm{cm}^{3}$ and a blend-type explosive (mixture of emulsion explosive and ammonium nitrate) with a density of $1.15 \mathrm{~g} / \mathrm{cm}^{3}$. Their performances are predicted at 165 and $250 \mathrm{~mm}$ blasthole diameters confined in two rock types (kimberlite and limestone). Input explosive parameters are given in Tables I and II for the DeNE and JWL++, respectively. DeNE uses the Vixen-i and JWL++ employs the Cheetah ideal detonation codes to determine the required ideal detonation parameters. The inputs (explosive composition and unreacted explosive density) used in these codes are same.

In addition to the explosive data, the codes require the rock and size effect (experimental unconfined VoD versus charge diameter) data as input. These are given in Tables III and IV, 
Table I. Explosive data for the DeNE [1].

\begin{tabular}{lcc}
\hline Parameter & ANFO1 & Blend1 \\
\hline$\rho_{0}\left(\mathrm{~g} / \mathrm{cm}^{3}\right)$ & 0.8 & 1.15 \\
$D_{\mathrm{CJ}}(\mathrm{km} / \mathrm{s})$ & 4.845 & 6.218 \\
$q(\mathrm{MJ} / \mathrm{kg})$ & 3.833 & 2.976 \\
$\gamma_{\mathrm{CJ}}$ & 2.777 & 2.999 \\
$\gamma_{0}$ & 1.339 & 1.338 \\
$\mathrm{MFL}$ & 0 & 0.65 \\
$\rho_{\mathrm{S}}\left(\mathrm{g} / \mathrm{cm}^{3}\right)$ & 1 & 1 \\
$\rho_{\mathrm{L}}\left(\mathrm{g} / \mathrm{cm}^{3}\right)$ & 1 & 1.39 \\
$C_{0}(\mathrm{~km} / \mathrm{s})$ & 0.92 & 1.85 \\
$S_{1}$ & 1.4 & 1.4 \\
\hline
\end{tabular}

Table II. JWL EoS's used the JWL++ model. The hydrocode units of $\mathrm{cm} /$ Mbar are listed.

\begin{tabular}{lcc}
\hline & ANFO1 & Blend1 \\
\hline$\rho_{0}$ & 0.80 & 1.15 \\
$A$ & 1.463306 & 2.844195 \\
$B$ & 0.01125895 & 0.02754112 \\
$R_{1}$ & 5.5 & 4.8 \\
$R_{2}$ & 1.0 & 1.2 \\
$\omega$ & 0.29 & 0.31 \\
$E_{0}$ & 0.0349 & 0.0416 \\
$\Gamma_{\mathrm{CJ}}+1$ & 3.862736 & 4.035845 \\
$D$ & 0.4510 & 0.5920 \\
$C$ & 0.008101 & 0.008130 \\
$P_{\mathrm{CJ}}$ & 0.042 & 0.100 \\
$C_{0}(\mathrm{~cm} / \mu \mathrm{s})$ & 0.023 & 0.067 \\
$S_{1}$ & 2.0 & 2.0 \\
$n$ & 7.0 & 7.0 \\
$\kappa\left(\mathrm{Mbar}^{-1}\right)$ & 2463 & 194 \\
\hline
\end{tabular}

Table III. Rock data used in DeNE and JWL++ [1].

\begin{tabular}{lccccc}
\hline & \multicolumn{2}{c}{ DENE } & & \multicolumn{2}{c}{ JWL++ } \\
\cline { 2 - 3 } \cline { 5 - 6 } Rock & $\rho_{\mathrm{r}}\left(\mathrm{g} / \mathrm{cm}^{3}\right)$ & $v_{\mathrm{p}}(\mathrm{km} / \mathrm{s})$ & & $C_{0}(\mathrm{~km} / \mathrm{s})$ & $S_{1}$ \\
\hline Kimberlite & 2.264 & 2.521 & & 2.276 & 1.371 \\
Limestone & 2.679 & 6.435 & & 4.563 & 1.055 \\
\hline
\end{tabular}

respectively. Unconfined VoDs were measured in a wide range of diameters 63-241 $\mathrm{mm}$ for ANFO1 and $58-236 \mathrm{~mm}$ for Blend1. In these measurements, the critical diameters were not observed but estimated to be 56 and $40 \mathrm{~mm}$ for ANFO1 and Blend1, respectively. 
Table IV. The unconfined size effect data for ANFO1 and Blend1 [1].

\begin{tabular}{ccccc}
\hline ANFO1 & $d(\mathrm{~mm})$ & $R_{0}(\mathrm{~mm})$ & $1 / R_{0}(1 / \mathrm{mm})$ & $D(\mathrm{~km} / \mathrm{s})$ \\
\hline 241 & 120.5 & 0.0083 & 4.13 \\
& 154 & 77.0 & 0.0130 & 3.82 \\
154 & 77.0 & 0.0130 & 3.85 \\
154 & 77.0 & 0.0130 & 3.58 \\
103 & 51.5 & 0.0194 & 2.57 \\
103 & 51.5 & 0.0194 & 2.70 \\
& 87 & 43.5 & 0.0230 & 2.50 \\
87 & 43.5 & 0.0230 & 2.51 \\
& 63 & 31.5 & 0.0317 & 2.13 \\
& & & \\
Blend1 & 118.0 & 0.0085 & 5.58 \\
& 236 & 118.0 & 0.0085 & 5.66 \\
& 236 & 118.0 & 0.0085 & 5.71 \\
& 236 & 75.0 & 0.0133 & 5.15 \\
150 & 75.0 & 0.0133 & 5.41 \\
& 150 & 75.0 & 0.0133 & 5.62 \\
150 & 65.0 & 0.0154 & 4.81 \\
& 130 & 65.0 & 0.0154 & 4.90 \\
& 130 & 65.0 & 0.0154 & 5.06 \\
& 130 & 50.5 & 0.0198 & 4.12 \\
101 & 41.0 & 0.0244 & 3.95 \\
82 & 41.0 & 0.0244 & 4.13 \\
& 82 & 41.0 & 0.0244 & 4.34 \\
82 & 41.0 & 0.0244 & 4.41 \\
82 & 41.0 & 0.0244 & 4.67 \\
82 & 34.5 & 0.0290 & 3.61 \\
69 & 34.5 & 0.0290 & 3.69 \\
69 & 34.5 & 0.0290 & 3.79 \\
69 & 34.5 & 0.0290 & 3.82 \\
69 & 34.5 & 0.0290 & 3.94 \\
69 & 29.0 & 0.0345 & 3.78 \\
\hline 58 & & &
\end{tabular}

\section{RESULTS AND COMPARISON OF THE CODES}

The fits provided by DeNE are illustrated in Figure 2. It appears that both explosives have different size effect curve and ANFO1 is more slow-reacting explosive than Blend1.

The correct rate constant in JWL++ is found by running the smallest measured unconfined diameter sample until a match is obtained. Then all the sizes are run for comparison with size effect data, as seen in Figures 3 and 4 for ANFO1 and Blend1, respectively. The infinite-radius detonation velocity stays pinned; changing the rate constant rotates the line up or down.

Figure 5 shows the ratio $U_{\mathrm{s}} / C_{0}$ as determined using JWL. If the ratio $U_{\mathrm{s}} / C_{0} \gg 1$, then we have the classic situation with a shock wave forming in the rock and trailing out behind the detonation front, as will be further considered below. If $U_{\mathrm{s}} / C_{0} \ll 1$, then no shock wave forms in the wall. Most of our sizes fall into the first category and only ANFO1/limestone lies on the border. Figure 6 shows the importance of this relative to running JWL++. If $U_{\mathrm{s}} / C_{0} \gg 1$, then the detonation velocity levels off with a thin shell of rock. If $U_{\mathrm{s}} / C_{0} \ll 1$, 


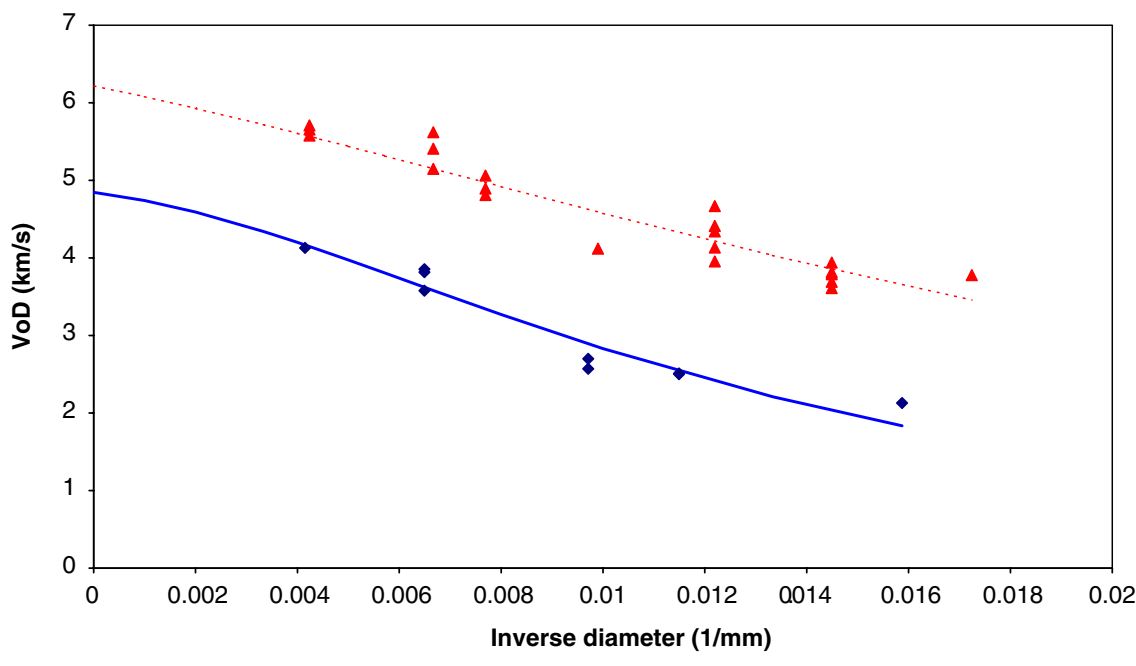

$\bullet$ ANFO_measured points _-ANFO_fit $\triangle$ Blend1_measured points $\cdots . .$. Blend1_fit

Figure 2. Unconfined VoD fits obtained from DeNE to the experimental data.

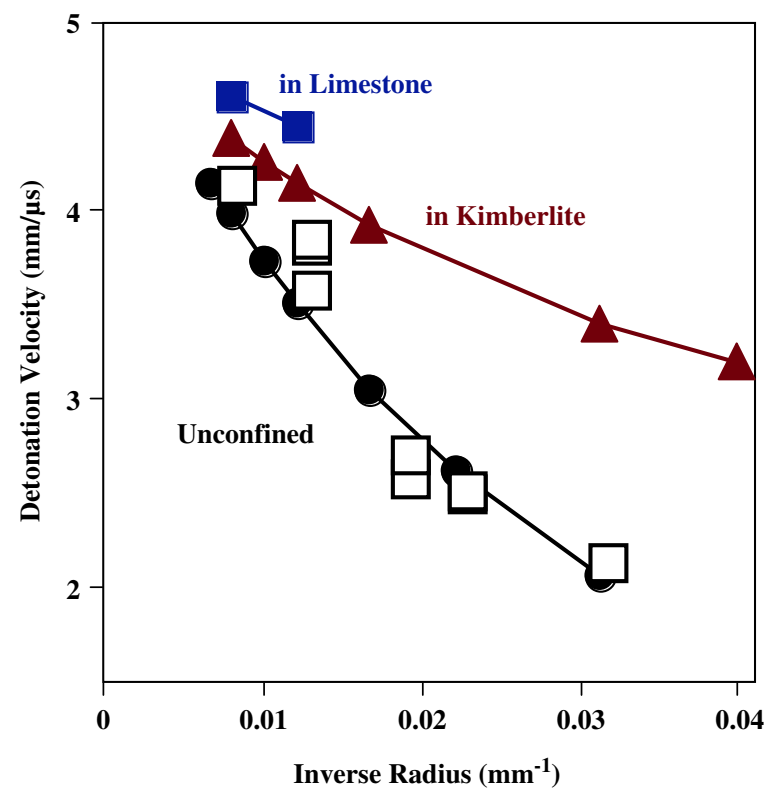

Figure 3. Unconfined VoD fits obtained from JWL++ for ANFO1. The empty squares are the unconfined data; the full triangles are the confined (kimberlite) data and the full squares are the confined (limestone) data. 


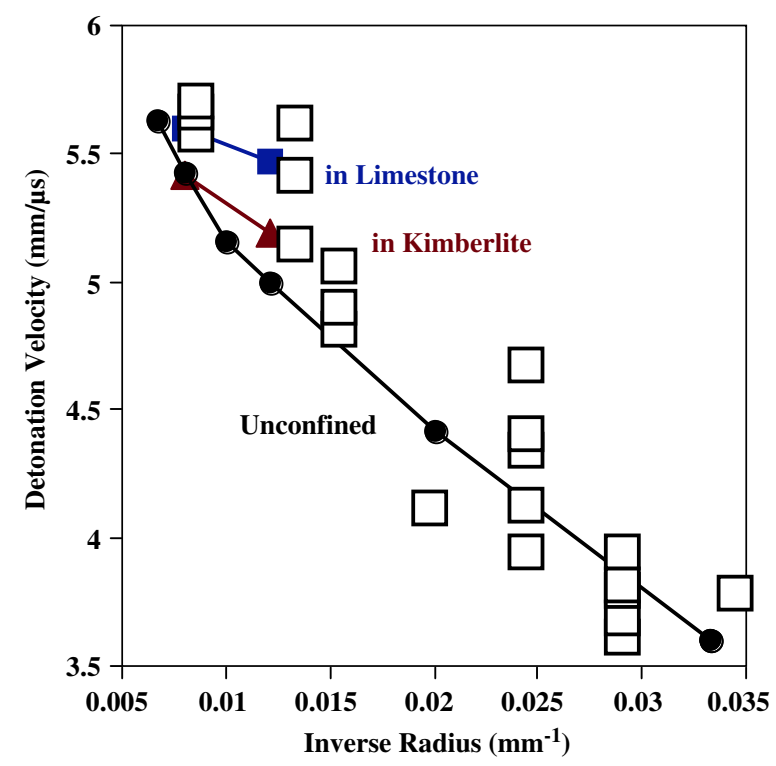

Figure 4. Unconfined VoD fits obtained from JWL++ for Blend1. The empty squares are the unconfined data; the full triangles are the confined (kimberlite) data and the full squares are the confined (limestone) data.

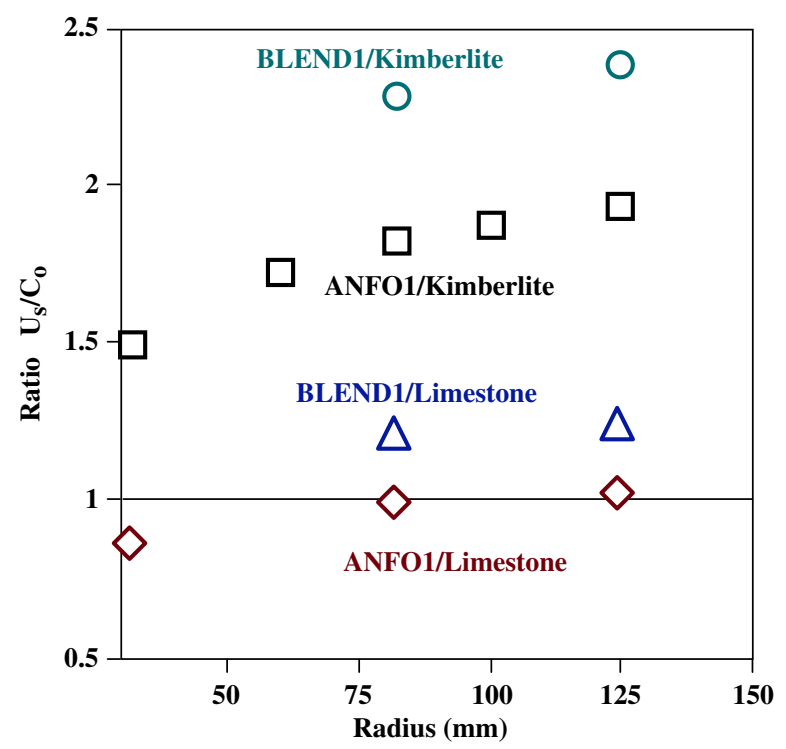

Figure 5. Plot of the ratio $U_{\mathrm{s}} / C_{0}$ as a function of radius. Above the line, shock, waves form in the wall; below the line, they do not. 


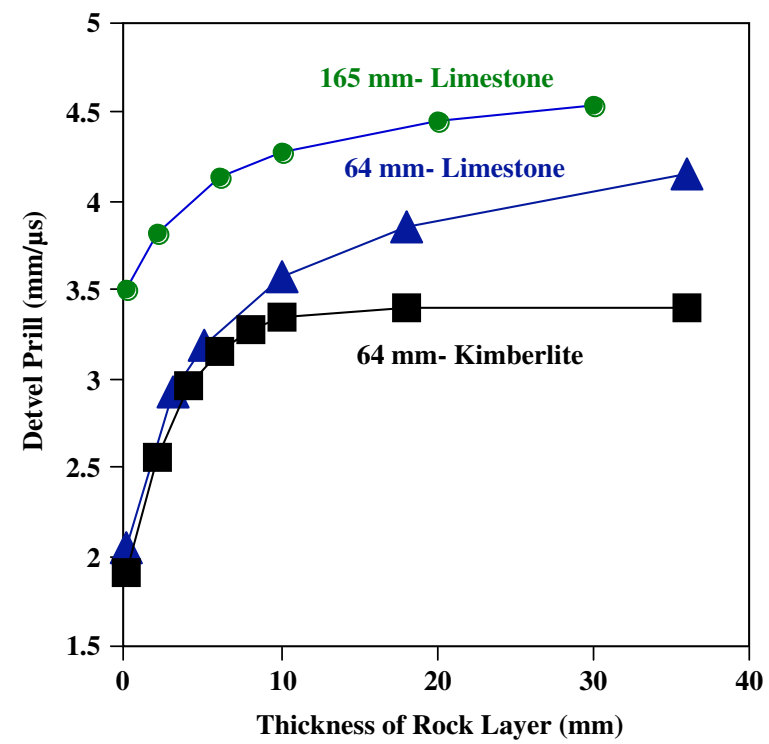

Figure 6. Effect of rock thickness with ANFO1 in JWL++. If $U_{\mathrm{s}} / C_{0}>1$, the detonation velocity levels off quickly (lowest line). If $U_{\mathrm{s}} / C_{0}<1$, it continues to grow (middle line).

We are set at $20 \mathrm{~mm}$ for most calculations.

Table V. Simulation results obtained using DeNE.

\begin{tabular}{lcccccccc}
\hline Case & Explosive & $d(\mathrm{~mm})$ & Rock & $D(\mathrm{~km} / \mathrm{s})$ & $p_{\text {CJ }}(\mathrm{GPa})$ & $v_{\mathrm{CJ}}\left(\mathrm{cm}^{3} / \mathrm{g}\right)$ & $\lambda_{\mathrm{CJ}}$ & $x_{\mathrm{CJ}}(\mathrm{mm})$ \\
\hline c1 & ANFO1 & 165 & Kimberlite & 3.927 & 3.211 & 0.985 & 0.721 & 80.8 \\
c2 & ANFO1 & 250 & Kimberlite & 4.325 & 3.961 & 0.956 & 0.872 & 46.3 \\
c3 & ANFO1 & 165 & Limestone & 4.030 & 3.407 & 0.983 & 0.787 & 68.8 \\
c4 & ANFO1 & 250 & Limestone & 4.390 & 4.091 & 0.949 & 0.884 & 87.2 \\
c5 & BLEND1 & 165 & Kimberlite & 5.398 & 8.161 & 0.686 & 0.897 & 30.4 \\
c6 & BLEND1 & 250 & Kimberlite & 5.701 & 9.196 & 0.672 & 0.932 & 22.7 \\
c7 & BLEND1 & 165 & Limestone & 5.479 & 8.451 & 0.679 & 0.902 & 46.3 \\
c8 & BLEND1 & 250 & Limestone & 5.755 & 9.343 & 0.672 & 0.944 & 38.2 \\
\hline
\end{tabular}

then the detonation velocity keeps rising with ever more rock. Running ANFO1/limestone lies in between, but our usual thickness of $20 \mathrm{~mm}$ will not give a true equilibrium value for this problem.

The results obtained for a number of simulations including different explosive/rock/blasthole diameter combinations are tabulated in Tables V and VI for DeNE and JWL++, respectively. The key flow properties (VoD, pressure, specific volume, extent of reaction and reaction zone length) at the sonic locus on the charge axis have been compared, as the DeNE calculates the detonation parameters only at the charge axis. Table VII shows the percentage differences in each parameter. It is shown that the flow parameters at the sonic line predicted using both codes agree within 10\% (average) error except for the reaction zone length. The discrepancies 
Table VI. Simulation results obtained using JWL++.

\begin{tabular}{lcccccccccc}
\hline Case & Explosive & $\begin{array}{c}d \\
(\mathrm{~mm})\end{array}$ & $\begin{array}{c}D \\
(\text { Rock })\end{array}$ & $\begin{array}{c}D \\
(\mathrm{~km} / \mathrm{s})\end{array}$ & $\begin{array}{c}p_{\mathrm{CJ}} \\
(\mathrm{GPa})\end{array}$ & $\begin{array}{c}v_{\mathrm{CJ}} \\
\left(\mathrm{cm}^{3} / \mathrm{g}\right)\end{array}$ & $\lambda_{\mathrm{CJ}}$ & $\begin{array}{c}\left\langle x_{\mathrm{e}}\right\rangle \\
(\mathrm{mm})\end{array}$ & $\begin{array}{c}\text { Edge angle } \\
(\mathrm{deg})\end{array}$ & $\begin{array}{c}\text { Zones in } \\
\left\langle x_{\mathrm{e}}\right\rangle\end{array}$ \\
\hline $\mathrm{c} 1$ & ANFO1 & 165 & Kimberlite & 4.15 & 3.24 & 1.046 & 0.888 & 28.2 & 12 & 23 \\
$\mathrm{c} 2$ & ANFO1 & 250 & Kimberlite & 4.39 & 3.68 & 1.018 & 0.931 & 31.5 & 6 & 19 \\
$\mathrm{c3}$ & ANFO1 & 165 & Limestone & 4.46 & 3.83 & 1.002 & 0.920 & 29.0 & 4 & 35 \\
$\mathrm{c} 4$ & ANFO1 & 250 & Limestone & 4.61 & 4.13 & 0.990 & 0.956 & 36.2 & 4 & 22 \\
c5 & BLEND1 & 165 & Kimberlite & 5.19 & 7.20 & 0.708 & 0.923 & 15.8 & 16 & 13 \\
c6 & BLEND1 & 250 & Kimberlite & 5.42 & 8.02 & 0.692 & 0.957 & 18.4 & 15 & 11 \\
c7 & BLEND1 & 165 & Limestone & 5.47 & 8.17 & 0.691 & 0.968 & 20.4 & 7 & 16 \\
c8 & BLEND1 & 250 & Limestone & 5.62 & 8.79 & 0.678 & 0.980 & 23.3 & 7 & 14 \\
\hline
\end{tabular}

Table VII. Comparison of the flow parameters obtained from the DeNE and JWL++ using an error analysis.

\begin{tabular}{lccccc}
\hline & $\begin{array}{c}\text { Difference } \\
\text { in } D(\%)\end{array}$ & $\begin{array}{c}\text { Difference } \\
\text { in } p(\%)\end{array}$ & $\begin{array}{c}\text { Difference } \\
\text { in } v(\%)\end{array}$ & $\begin{array}{c}\text { Difference } \\
\text { in } \lambda(\%)\end{array}$ & $\begin{array}{c}\text { Difference } \\
\text { in } x_{\mathrm{CJ}}(\%)\end{array}$ \\
\hline Average & 4.3 & 6.9 & 3.5 & 9.0 & 46.9 \\
Min & 0.2 & 0.9 & 0.9 & 2.7 & 18.9 \\
Max & 10.7 & 12.8 & 6.5 & 23.2 & 65.1 \\
\hline
\end{tabular}

are believed to be owing to the following: different rate law, EoS, shock calculation method used in modelling; approximations and numerical technique employed. The reaction zone length predicted using DeNE appears to be overestimated.

All quantities obtained from JWL++ are listed on the axis of revolution. In JWL++, the reaction zone is given by $\left\langle x_{\mathrm{e}}\right\rangle$ and the number of zones in it are listed. All are considerably beyond 4 , so that the reactive flow model is showing the model off correctly. The edge angle is often undercalculated in JWL++, which cannot capture the sudden lag near the edge that is often seen. Along with this, JWL++ may also underestimate the reaction zone length.

Both models follow the expected trends: for a given explosive and rock type, the larger the diameter is, the higher the $\mathrm{VoD}$, pressure and extent of reaction and the lower the specific volume. For a given explosive type and blasthole diameter, $\mathrm{VoD}$, pressure and extent of reaction increase with the stiffer (higher strength) rock. Both models appear to predict similar explosive performance. Therefore, these codes are believed to provide a good insight into the prediction of non-ideal detonation characteristics of commercial explosives.

\section{DISCUSSION ON THE EXPLOSIVE/ROCK INTERFACE}

The main difference between the analytical model (DeNE) and the hydrocode (JWL++) is that JWL++ determines the flow properties in all regions of the DDZ and thus permit us to examine the explosive/rock interface more closely. 


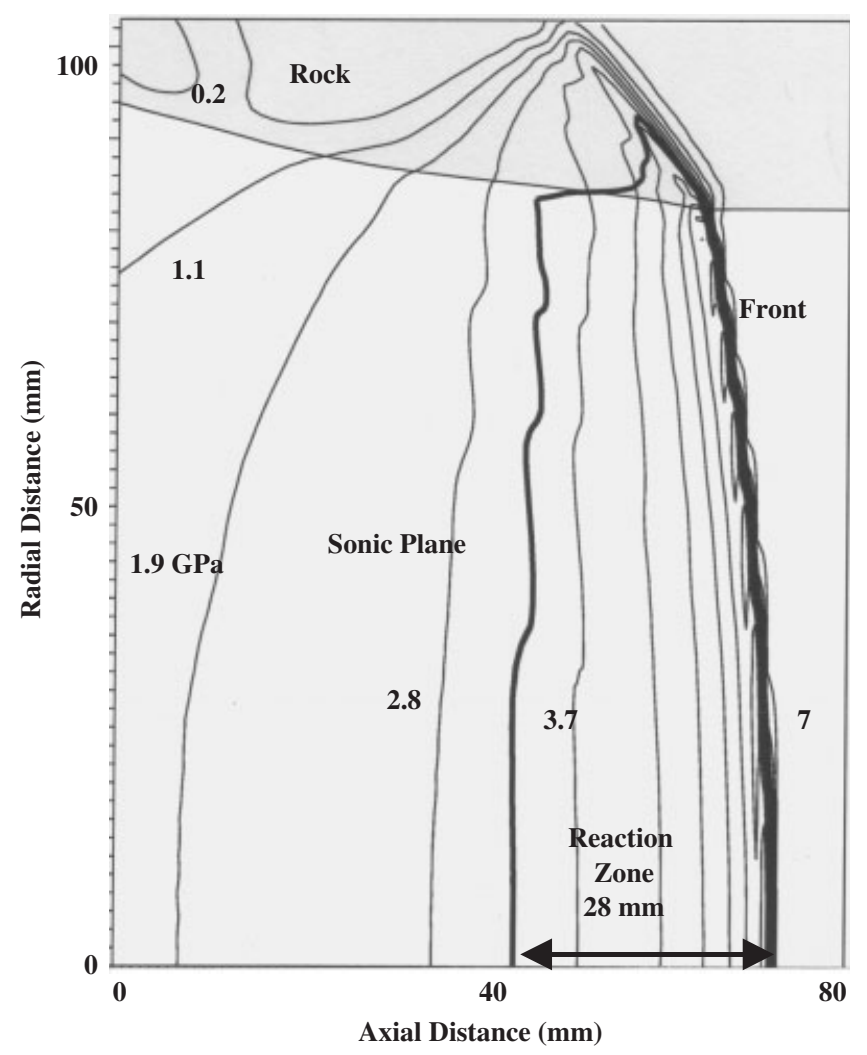

Figure 7. $U_{\mathrm{s}} / C_{0} \gg 1$ : JWL++ view of $165 \mathrm{~mm}$ diameter ANFO1 in kimberlite. The detonation moves left to right with a steady state value of $4.15 \mathrm{~mm} / \mu \mathrm{s}$. The rock layer is at the top. The contours are pressure in GPa. The sonic plane is the back of the reaction zone, which is about $28 \mathrm{~mm}$ wide on the axis. A clear shock wave is seen in the rock, which here reflects back at the outer edge.

Firstly, we compared the pressure plots for ANFO1 confined in kimberlite and limestone at $165 \mathrm{~mm}$ blastholes, as shown in Figures 7 and 8, respectively. ANFO1's performance in kimberlite and limestone falls into $U_{\mathrm{s}} / C_{0} \gg 1$ and $U_{\mathrm{s}} / C_{0} \sim 1$, respectively. If the ratio $U_{\mathrm{s}} / C_{0} \gg 1$, then we have the classic situation with a shock wave forming in the rock and trailing out behind the detonation front (Figure 7). The rock is also supersonic in the problem.

However, the $165 \mathrm{~mm}$ ANFO1 confined in limestone shown in Figure 8 falls in the $U_{\mathrm{s}} / C_{0}<1$ group, if barely. Here, the rock is no longer supersonic, it is subsonic, so there is no shock wave in the rock. We do not get the familiar bow-wave in the rock, but instead we have a bulb of declining pressure, which runs along with the detonation front. The front of the bulb is in front of the detonation front and it precompresses the explosive on the edge. This is in line with Eden and Belcher's [20] findings.

Similar simulations have been carried out for Blend1 in $165 \mathrm{~mm}$ blasthole confined in limestone and kimberlite. Because Blend1 confined in limestone and kimberlite falls in $U_{\mathrm{s}} / C_{0}>1$, shock waves form in the rock as shown in Figures 9 and 10, respectively. Figure 11 shows 


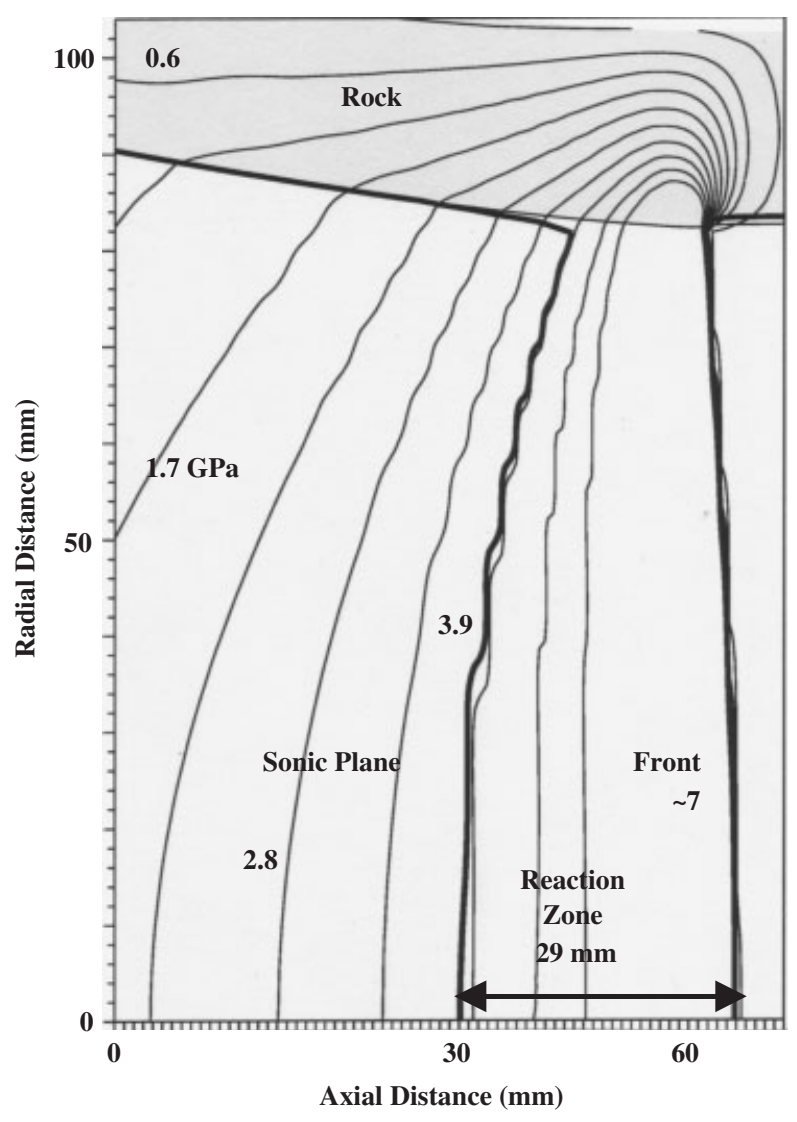

Figure 8. $U_{\mathrm{s}} / C_{0} \sim 1$ : Code view of $165 \mathrm{~mm}$ diameter ANFO1 in limestone. Here the rock conducts energy faster than the explosive moves and we have no shock wave in the rock. Instead we have a radiating bulb of pressure, where the contours are pressure. The pressure wave in the rock even leads the detonation front. The detonation velocity is $4.46 \mathrm{~mm} / \mu \mathrm{s}$.

the pressure plot of Blend 1 confined in limestone at $250 \mathrm{~mm}$ diameter blasthole. It is shown that the rock is experiencing the shock front (spike) pressure and the pressure in the rock declines sharply. Figure 12 plots the pressure history using the DeNE for the conditions given in Figure 11. It appears that the pressure values at the shock front and sonic line (plane) agree well. Furthermore, it can be concluded that discrepancies between the pressures at the charge axis and edge are insignificant (Figure 11). This suggests that the pressure history of the DeNE may be used as input to a blasting model with sufficient accuracy for practical blasting operations.

The other conclusions derived from the JWL++ simulations are as follows:

- The DDZ contact at the borehole wall is finite suggesting that rock experiences the pressure at the shock front firstly. Thus, the pressure history ( $p-t$ or $p-v$ curves) used in the blasting models should start from the shock front pressure. 


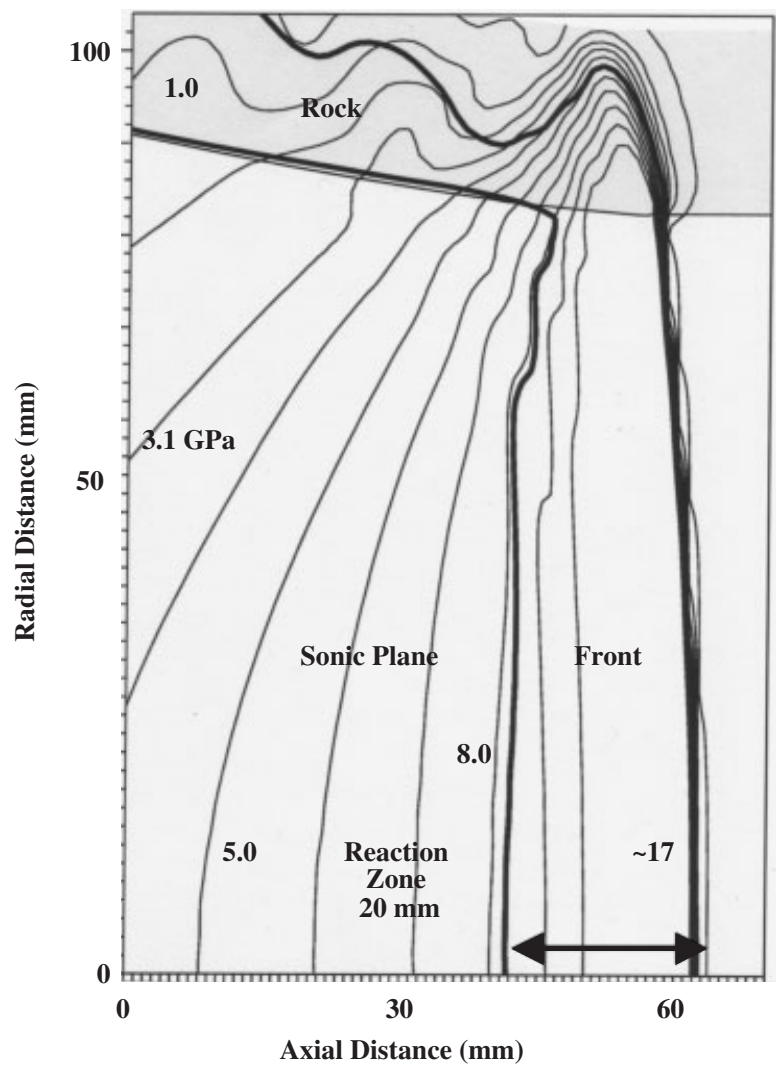

Figure 9. Blend 1 in limestone at $165 \mathrm{~mm}$ with the $U_{\mathrm{s}} / C_{0}>1$ shock wave in the rock.

- Shock shape is spherical in these confined cases.

- The material properties along with the different $U_{\mathrm{s}} / C_{0}$ ratios have profound effect on the local behaviour of the explosive/rock system.

Recent hydrocode simulations carried out by Aslam and Bdzil [21] and Sharpe [22] suggest that reaction zone contact at the explosive/metal interface is finite. This agrees with the first point given above. Unlike these studies, this paper focuses on the commercial explosive/rock combination, which is believed to offer a practical insight into blasting applications in the mining industry.

The simulations carried out using the DeNE and JWL++ codes enable the comparison of the performance of the explosives and thereby the selection of a suitable explosive matching the given geotechnical environment. Suppose a limestone quarry operates with a blasthole diameter of $165 \mathrm{~mm}$. The rock experiences higher pressures (Tables V and VI) and shock waves are formed with the use of Blend1 product. As limestone is a high strength rock, an explosive with higher VoD and pressure is required to blast such rock. Therefore, Blend1 should be a better choice for this case. On the other hand, kimberlite, which is a low strength rock, experiences lower pressure with the use of ANFO1 (Tables V and VI). As an explosive with lower VoD 


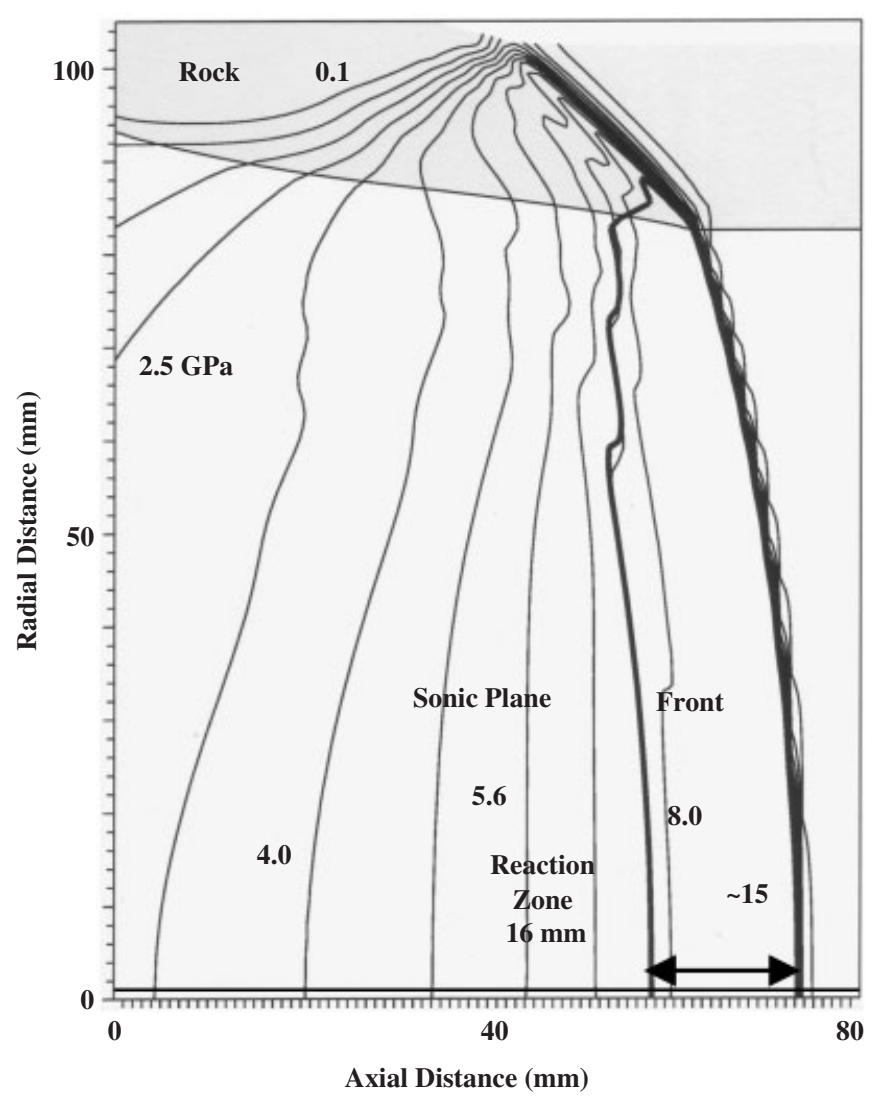

Figure 10. Blend1 in kimberlite which also has $U_{\mathrm{s}} / C_{0} \gg 1$ with a shock wave in the rock.

and pressure performs better in weak rocks, ANFO1 should be preferred in this case provided that blastholes are dry.

\section{COMPARISON OF THE MEASURED AND PREDICTED DETONATION VELOCITIES}

Confined VoDs predicted in three cases (2,3 and 5) presented in Tables V and VI are compared with the available measured VoDs as shown in Table VIII. Average errors in the VoD predictions using the DeNE and JWL++ are 2.3 and 5.0\%, respectively. This is found to be within the experimental error range $(2.2-7.2 \%)$ in the $\mathrm{VoD}$ measurements. Hence, it can be concluded that the predictive capabilities of both codes are sufficient for practical blasting applications (Table IX).

As discussed in Section 1, all non-ideal detonation models excluding CPeX cannot model the non-ideal explosives confined in rock. Thus, the DeNE and JWL++ could not be compared to 


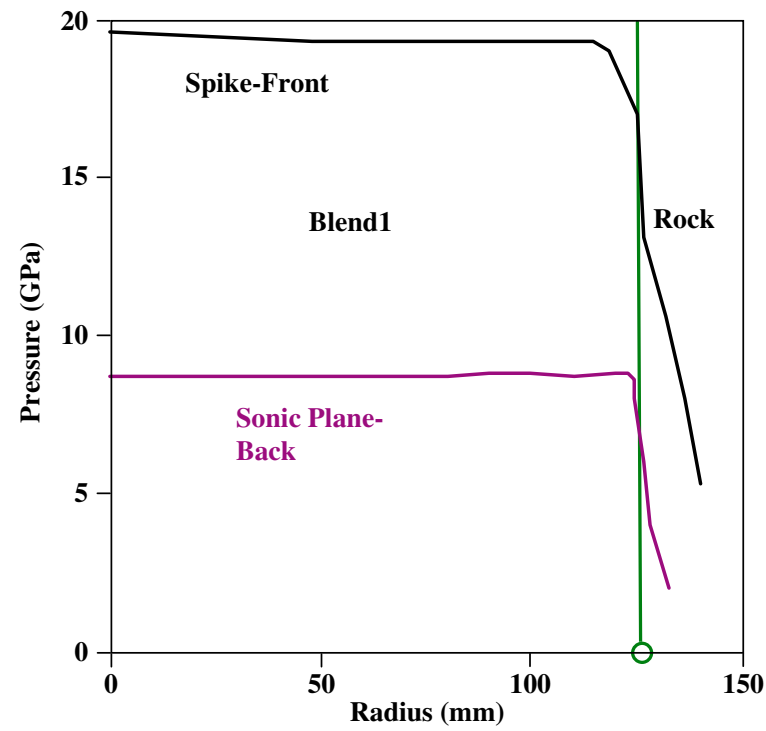

Figure 11. JWL++ view of the pressure across the radius of $125 \mathrm{~mm}$ Blend1 in limestone. The top curve is the maximum pressure associated with the spike. The lower curve is the pressure at the back of the reaction zone (sonic plane) is associated with the CJ point.

The pressures decline rapidly at the rock interface.
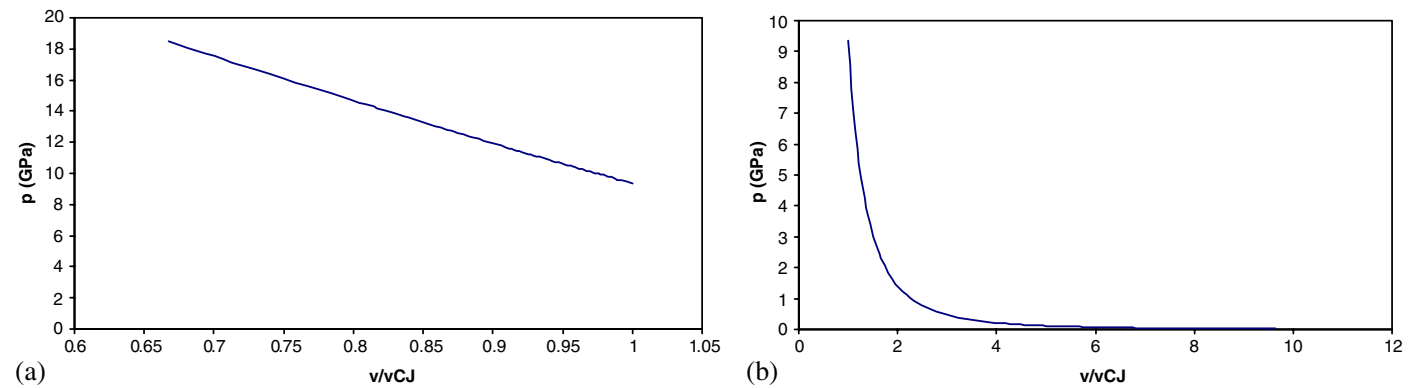

Figure 12. The pressure history (at charge axis) for $250 \mathrm{~mm}$ Blend 1 confined in limestone using DeNE: (a) at the DDZ-between shock front and sonic line; and (b) Taylor wave.

the other codes. $\mathrm{CPeX}$ is proprietary and not readily available to the industry. It was noted that the confinement calculations in CPeX are not reliable and the kinetic rate law is complex and include a large number of adjustable parameters [7]. Therefore, the codes presented in this paper should provide acceptable predictions of explosive performance in rock blasting considering the good agreement between the measured and predicted VoDs and model evaluations given Sections 5 and 6 . 
Table VIII. Comparison of the confined VoDs predicted using DeNE and JWL++.

\begin{tabular}{lccc}
\hline Case & $\begin{array}{c}\text { VoD }(\mathrm{km} / \mathrm{s}) \\
(\mathrm{DeNE})\end{array}$ & $\begin{array}{c}\mathrm{VoD}(\mathrm{km} / \mathrm{s}) \\
(\mathrm{JWL}++)\end{array}$ & $\begin{array}{c}\mathrm{VoD}(\mathrm{km} / \mathrm{s}) \\
\text { (experimental) }\end{array}$ \\
\hline c2 [23] & 4.325 & 4.390 & $4.256^{*}$ \\
c3 [23] & 4.030 & 4.460 & 4.010 \\
c5 [1] & 5.398 & 5.190 & $5.159 \pm 0.300$ \\
\hline
\end{tabular}

* Obtained from a case study conducted by Bilgin et al. [23] at a similar rock type, explosive and blasthole diameter.

Table IX. Comparison of the DeNE, JWL++ and DSD models.

\begin{tabular}{lcccccc}
\hline Model & $d(\mathrm{~mm})$ & $\mathrm{VoD}(\mathrm{km} / \mathrm{s})$ & $p_{\mathrm{s}}(\mathrm{GPa})$ & $p_{\mathrm{CJ}}(\mathrm{GPa})$ & $x_{\mathrm{CJ}}(\mathrm{mm})$ & $\lambda_{\mathrm{CJ}}$ \\
\hline DeNE & 32 & 4.1 & 5.098 & 2.814 & 6.098 & 0.279 \\
JWL++ & & 4.0 & 5.020 & 3.400 & 8.970 & 0.317 \\
DSD model & & 5.6 & 12.364 & 7.998 & 4.005 & 0.647 \\
DeNE & 72 & 5.5 & 12.300 & 7.870 & 9.150 & 0.639 \\
JWL++ & & & & &
\end{tabular}

\section{CONCLUDING REMARKS}

The non-ideal detonation performances of two commercial explosives have been determined using two available codes: DeNE and JWL++. These two codes differ in that DeNE is based on a pseudo-one-dimensional theory and uses statistical expressions for detonation velocity and shock curvature and valid on the central stream-tube. The JWL++, on the other hand, is a hydrocode running in a 2-D arbitrary Lagrangian-Eulerian code with CALE-like properties and can determine the flow properties in all stream lines within the reaction zone.

The key flow properties (VoD, pressure, specific volume, extent of reaction and reaction zone length) at the sonic locus on the charge axis have been compared with two commercial explosives. It is shown that the mean flow parameters determined using both codes agree within $10 \%$ error range except for the reaction zone length. The reaction zone lengths predicted using DeNE and JWL++ appear to be overestimated or underestimated.

Both models follow the expected trends: for a given explosive and rock type, the larger the diameter is, the higher the $\mathrm{VoD}$, pressure and extent of reaction and the lower the specific volume are. For a given explosive type and blasthole diameter, $\mathrm{VoD}$, pressure and extent of reaction increase with the stiffer (higher strength) rock. Both models appear to predict similar explosive performance.

The pressure contours were compared for two explosives at $165 \mathrm{~mm}$ blastholes in limestone and kimberlite. It appears that when the $U_{\mathrm{s}} / C_{0}$ is close to 1 or slightly less than 1 , the shock wave does not form in the rock. However, it forms for the cases with $U_{\mathrm{s}} / C_{0}>1$. The rock experiences the shock pressure and the contact between the blasthole wall and the DDZ is finite. The results also suggest that the pressures in the rock decline sharply. 
The DeNE and JWL++ codes have been verified with the measured in-hole detonation velocity data. Results from this validation and model evaluation show theirs applicability to rock blasting.

The close predictions of non-ideal detonation performance of commercial explosives using DeNE and JWL++ is promising and these two codes can be used to determine the performance of explosive confined in a given rock type within an acceptable accuracy. The JWL++ appears to complement the DeNE code as it calculates the flow properties in all stream lines within the reaction zone and gives a good insight into the understanding of the explosive/rock interface. As the discrepancies between the JWL++ pressures at charge axis and edge are insignificant, the pressure history of the DeNE given at the charge axis can be used as input to a blasting model with sufficient accuracy for practical blasting applications.

\section{NOMENCLATURE}

$\begin{array}{ll}b_{1} & \text { pressure exponent } \\ C & \text { sound speed } \\ C_{0} & U_{\mathrm{s}}-u_{\mathrm{p}} \text { coefficient/sound speed in the code } \\ d & \text { charge diameter } \\ D & \text { detonation velocity } \\ E & \text { specific internal energy } \\ E_{\mathrm{d}} & \text { detonation energy along the isentrope } \\ E_{0} & \text { total energy of detonation } \\ E_{\mathrm{t}} & \text { turbulent stored energy } \\ E_{\mathrm{s}} & \text { internal energy } \\ \text { EoS } & \text { equation of state } \\ G_{1} & \text { rate constant } \\ k & \text { rate constant } \\ \mathrm{MFL} & \text { mass fraction of liquid } \\ n & \text { unreacted EoS coefficient } \\ p & \text { pressure } \\ q & \text { heat of reaction } \\ Q & \text { artificial viscosity } \\ R_{0} & \text { initial explosive radius } \\ S_{1} & U_{\mathrm{s}}-u_{\mathrm{p}} \text { coefficient } \\ u_{\mathrm{p}} & \text { particle velocity } \\ U_{\mathrm{s}} & \text { shock velocity } \\ v & \text { specific volume } \\ v_{\mathrm{p}} & \text { P-wave velocity of intact rock } \\ \text { VoD } & \text { velocity of detonation } \\ x & \text { distance } \\ \left\langle x_{\mathrm{e}}\right\rangle & \text { average reaction zone thickness in JWL++ }\end{array}$

\section{Greek letters}

$\gamma \quad$ adiabatic gamma coefficient

$\gamma_{0} \quad$ ideal gas gamma

Copyright (C) 2005 John Wiley \& Sons, Ltd.

Int. J. Numer. Meth. Engng 2005; 64:1889-1914 


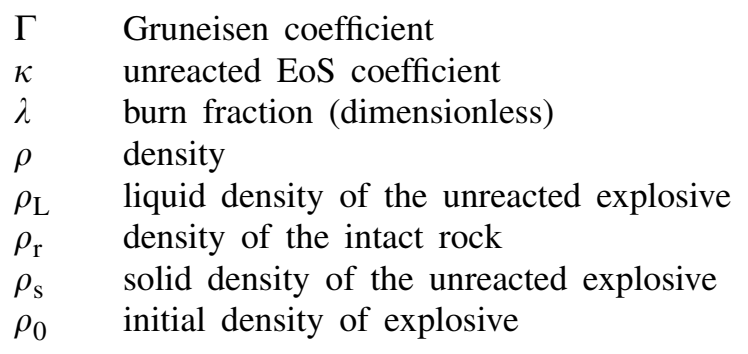

\section{Subscripts}

$\begin{array}{ll}\text { CJ } & \text { Chapman-Jouguet } \\ \mathrm{p} & \text { product phase } \\ \mathrm{s} & \text { shock front } \\ \mathrm{X} & \text { unreacted phase }\end{array}$

\section{APPENDIX A: THE INITIAL CONDITIONS}

The initial conditions $(t=0)$ are

$$
\begin{aligned}
& u=u_{\mathrm{S}}(D) \\
& p=p_{\mathrm{s}}(D) \\
& A=1 \\
& \lambda=0 \\
& \omega=\frac{D-u_{\mathrm{S}}(D)}{R_{\mathrm{S}}\left(x_{\mathrm{CJ}}, d\right)} \\
& E=\frac{p_{\mathrm{S}}\left(v_{0}-v_{\mathrm{S}}\right)}{2} \\
& v=v_{\mathrm{S}}(D) \\
& \rho=\rho_{\mathrm{S}}(D) \\
& x=0
\end{aligned}
$$

Equations (A1), (A2), (A6), (A7) and (A8) can be obtained from the well-known RankineHugoniot jump conditions [9]:

Mass equation

$$
\frac{\rho_{1}}{\rho_{0}}=\frac{D}{D-u_{1}}=\frac{v_{0}}{v_{1}}
$$


Momentum equation

$$
p_{1}-p_{0}=\rho_{0} u_{1} D
$$

Energy equation

$$
E_{1}-E_{0}=\frac{1}{2}\left(p_{1}+p_{0}\right)\left(v_{0}-v_{1}\right)
$$

A relationship involving any two of the mass, momentum and energy

$$
p_{1}-p_{0}=\frac{D^{2}}{v_{0}}-\frac{D^{2}}{v_{0}^{2}} v_{1}
$$

which is obtained by eliminating the particle velocity term $u$ by manipulating the mass and momentum jump equations.

The Hugoniot equation

$$
p=\frac{C_{0}^{2}\left(v_{0}-v_{1}\right)}{\left[v_{0}-S\left(v_{0}-v_{1}\right)\right]^{2}}
$$

where $C_{0}$ and $S$ are shock Hugoniot parameters. $C_{0}$ is called the bulk sound speed with unit in $\mathrm{km} / \mathrm{s} . S$ is dimensionless.

Rankine-Hugoniot (A10)-(A12), Rayleigh line (A13) and Hugoniot (A14) relations are solved simultaneously to determine the shock parameters at the shock front. For the $p-v$ Hugoniot given above, the solution is obtained analytically and is simply

$$
v_{\mathrm{s}}=v_{0}\left[1-\frac{\left(1-C_{0} / D\right)}{S}\right]
$$

and $u_{\mathrm{s}}, p_{\mathrm{s}}$ and $E_{\mathrm{s}}$, evaluated at the shock are obtained by substitution into Equations (A10), (A14) and (A12), respectively.

\section{ACKNOWLEDGEMENTS}

The authors would like to acknowledge the support provided by Dr Gideon Chitombo, Prof. Bill Whiten and Mr Kai Riihioja of the JKMRC in the development of the DeNE code. The authors would also like to thank Mr Italo Onederra of the JKMRC for his suggestions.

\section{REFERENCES}

1. Esen S. A non-ideal detonation model for commercial explosives. Ph.D. Thesis, The University of Queensland, 2004 (unpublished).

2. Peugeout F, Sharp MW. Reactive models for hydrocodes: past, present and future. Report to NIMIC Member Nations, Brussels, Belgium, 2002.

3. Wood WW, Kirkwood JG. Diameter effect in condensed explosives. Journal of Chemical Physics 1954; 22:1920-1924.

4. Bdzil JB, Stewart DS. Modeling two-dimensional detonations with detonation shock dynamics. Physics of Fluids A 1 1989; 7:1261-1267.

5. Bdzil JB, Aslam TD, Short M. DSD front models: nonideal explosive detonation in ANFO. Twelfth International Symposium on Detonation, San Diego, California, U.S.A., 2002. 
6. Kirby IJ, Leiper GA. A small divergent detonation theory for intermolecular explosives. 8th International Symposium on Detonation, Albuquerque, U.S.A., 1985; 176-186.

7. Byers Brown W. Critical review of theories of steady non-ideal two-dimensional detonation of condensed explosives. Confidential Report to HSBM Participants, Mass Action, U.K., 2002.

8. Souers PC, Anderson S, McGuire E, Vitello P. JWL++: a simple reactive flow code package for detonation. Propellants, Explosives, Pyrotechnics 2000; 25:54-58.

9. Cooper PW. Explosives Engineering. VCH Publishers Inc.: New York, 1996.

10. Persson P, Holmberg R, Lee J. Rock Blasting and Explosives Engineering. CRC Press: Boca Raton, FL, 1993.

11. Braithwaite M, Farran T, Gladwell I, Lynch PM, Minchinton A, Parker IB, Thomas RM. A detonation problem posed as a differential/algebraic boundary value problem. Mathematical Engineering in Industry 1990; 3(1):45-57.

12. Fickett W, Davis WC. Detonation: Theory and Experiment. Dover Publications: Mineola, U.S.A., 2000.

13. Sturgeon JA, Thomas RM, Gladwell I. Solving a singular DAE model of unconfined detonation. Computers and Chemistry 2001; 25:83-95.

14. Braithwaite M, Farran T, Gladwell I, Lynch PM, Minchinton A, Parker IB, Thomas RM. A detonation problem posed as a differential/algebraic boundary value problem. University of Manchester/UMIST Joint Numerical Analysis Report, 1989.

15. Esen S. A statistical approach to predict the effect of confinement on the detonation velocity of commercial explosives. Rock Mechanics and Rock Engineering 2004; 37(4):317-330.

16. Braithwaite M. Personal communication, 2003.

17. Schilling RJ, Harris SL. Applied Numerical Methods for Engineers Using Matlab and C. Brooks/Cole Publishing Company: Pacific Grore, CA, U.S.A., 2000.

18. Zukas JA, Walters WP. Explosive Effects and Applications. Springer: New York, U.S.A., 1998.

19. Davis WC. Equation of state for detonation products. Proceedings of the 11th Symposium (International) on Detonation, Snowmass, Colorado, 1998; 303-308.

20. Eden G, Belcher RA. The effects of inert walls on the velocity of detonation in EDC35, an insensitive high explosive. Proceedings of the Ninth Symposium (International) on Detonation, Portland, OR, 1989; 831-841.

21. Aslam TD, Bdzil JB. Numerical and theoretical investigations on detonation-inert confinement interactions. Twelfth International Symposium on Detonation, San Diego, California, U.S.A., 2002.

22. Sharpe GJ. HSBM Research Report on Rate Stick Simulations. Internal Report submitted to the HSBM Project participants, October 2003.

23. Bilgin HA, Esen S, Kilic M. Patarge project. Internal Report, Barutsan AS, Elmadag, Ankara, Turkey, 1999 (in Turkish). 